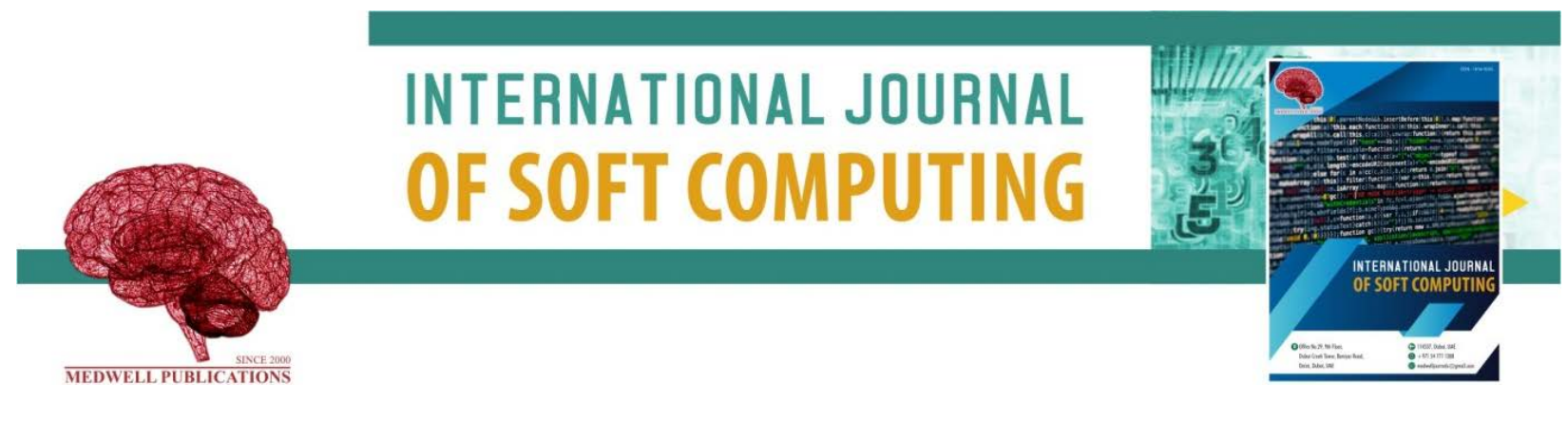

\title{
Improving the Performance of Heat Exchanger System
}

\author{
Rajesh Singla \\ B.R. Ambedkar National Institute of Technology, Jalandhar, India
}

Key words: Shell and tube heat exchanger system, PID controller, fuzzy logic controller, fractional order PID controller

\section{Corresponding Author:}

Rajesh Singla

Dr. B.R. Ambedkar National Institute of Technology, Jalandhar, India

Page No.: 77-85

Volume: 14, Issue 4, 2019

ISSN: 1816-9503

International Journal of Soft Compuring

Copy Right: Medwell Publications
Abstract: This study analyzes the performance of shell and tube type heat exchanger system using different controllers like PID controller, fractional order PID controller and fuzzy controller. The main purpose of a controller is to control the outlet temperature of a shell and tube type heat exchanger system to a particular set point value. The steady state performances of different controllers are analyzed with and without load disturbances to find out the best controller. The MATLAB simulation results exhibit that the fractional order PID controller gives low peak overshoot and low settling time when compared with PID controller and fuzzy logic controller.

\section{INTRODUCTION}

The heat exchanger is a crucial device used in chemical process industry dealing with the production or absorption of energy in the form of heat (Ismail et al., 2015). The heat exchanger is generally used in chemical process industries to transfer heat from the hot fluid through a solid wall to a cold fluid. Many types of heat exchangers are used but most of the industries use 'shelland-tube' type heat exchanger system (Duran et al., 2008).

'Shell-and-tube' type heat exchangers are most prevalent heat exchanger that can assist a wide range of operating temperatures and pressures. In the 'Shell-andtube' type heat exchanger one fluid passes through the tube and a second fluid passes through the space between the shell and tube. The heat transfer surface to volume ratio is very large as compared to coiled type and double pipe type of heat exchanger system (Padhee et al., 2011). Shell and tube type heat exchanger can be easily manufactured in large size and configurations. They can operate at high temperatures and pressures and they can be easily disassembled for periodic maintenance and cleaning. They are used in nuclear plant, power generation air conditioning, medical applications etc. Shell-and-tube type heat exchanger system is an enhancement of double pipe type heat exchanger system. It consists of a clump of pipes enclosed within a shell (Khare and Singh, 2010).

This study explains a work on Single Input Single Output (SISO) Model of shell-and-tube type heat exchanger system. This SISO Model is being built with the help of experimental data (Gopal, 2012). Input and output flow rate are the main parameters required for controlling the heating and cooling operation of the input fluid temperature at a desired output temperature. As per requirement of the process, the outlet temperature of the shell-and-tube type heat exchanger has to be maintained at a desired set point value. First of all, a conventional PID controller is implemented in feedback loop, so as to achieve the control objectives. PID controllers demonstrate a high peak overshoot and settling time which are undesirable. To minimize the peak overshoot and settling time, fuzzy logic controller and fractional order PID controller are implemented. This study reports three type of controllers which have been designed to achieve the control objectives and a comparative study between these controllers are done. 
Int. J. Soft Comput., 14 (4): 77-85, 2019

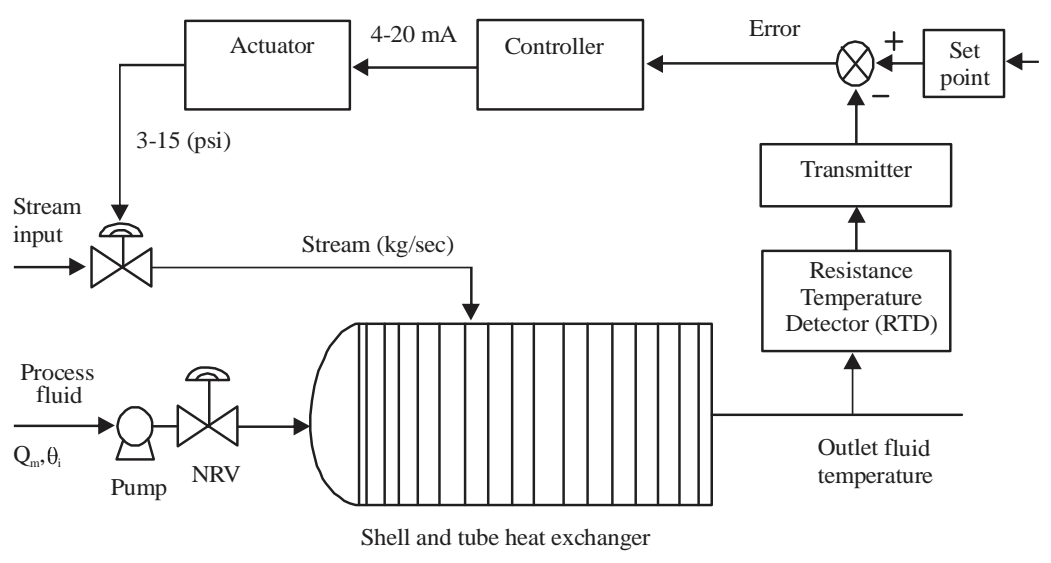

Fig. 1: Control scheme of shell-and-tube heat exchanger system

Description of shell-and-tube heat exchanger: Heat exchanger transfers heat between two different fluids without mixing them. The dynamic characteristics of shell-and-tube type heat exchanger depend on many factors such as temperature difference, heat transfer area and flow rate of fluids. There is a wide application of shell-and-tube type heat exchanger system in industries like petroleum, petrochemical, power generation, nuclear power plant, refrigerator, etc. Typical interacting heating purpose chemical processes for heating consist of a chemical reactors and a shell and tube heat exchanger system. The output fluid of chemical reactor, also termed as process fluid is stored in a storage tank and then supplied to the shell-and-tube heat exchanger system. The super heated steam at $160^{\circ} \mathrm{C}$ is supplied from the boiler and flows through the shell whereas the process fluid flows through the tubes of the shell-and-tube heat exchanger system. The heat exchanger heats up the process fluid to a desired set point using super heated steam supplied from the boiler. The storage tank supplies the process fluid to a shell-and-tube type heat exchanger system using a pump and non returning valve. After the steam heats up the process fluid, the condensed steam at $110^{\circ} \mathrm{C}$ goes out of the shell-and-tube heat exchanger system. Two types of assumption have been considered in this paper. The first assumption is that the insulating wall of the heat exchanger system is of negligible heat storage capacity. The second assumption is that the inflow and outflow rate of process fluid are same, so that, the process fluid level is maintained constant in the shell-and-tube heat exchanger system. Controller is reverse acting in feedback process control loop, the air to open type valve is used. In the feedback path a sensing element like Resistance Temperature Detector (RTD) is used in the control architecture. A RTD is measures the temperature of the process variable (outlet fluid) and the measured value of RTD send to the transmitter unit; the transmitter unit converts the output of RTD to a standard signal in the range of 4-20 mA. The measured output value of signal of the transmitter unit is compared with the reference temperature (set point) whenever both are not same then an error signal is generated to the controller, controller takes a control action and then gives necessary command to the air to open valve via the actuator unit. The actuator unit converts the controller output in the range of 4-20 $\mathrm{mA}$ in to a standardized pressure signal of the range of 3-15 psi. The control valve actuates according to the controller signal and control valve allows the needed steam to enter in shell-and-tube heat exchanger as to maintain the outlet temperature of heat exchanger system (Ismail et al., 2015; Duran et al., 2008; Padhee et al., 2011). Mainly two types of disturbances are present in shell-and-tube heat exchanger system; first one is variation in input fluid flow $\left(\mathrm{Q}_{\mathrm{m}}\right)$ and second is variation in input fluid temperature $\left(\theta_{\mathrm{i}}\right)$. But in practical, the flow variation of input fluid is more spectacular than temperature variation in input fluid. Figure 1 shows the schematic diagram of feedback control in shell-and-tube heat exchanger system (Padhee, 2014).

\section{MATERIALS AND METHODS}

Mathematical modeling: Experimental data is used for mathematical modeling of heat exchanger system, actuator, valve and sensor. The process experimental data s shown Table 1 (Gopal, 2012). From the experimental data, the transfer function model of the system is derived. The transfer functions of different component of the heat exchanger system are shown in Table 2.

Proportional-Integral-Derivative (PID) controller: The PID controller is the most popular and reliable operative controller in process industries. PID controller structure is simple, easy to understand and manual tuning is possible. Continuous time PID controller comprises three different controllers that are proportional+integral+derivative. Ideal PID controller equation is shown (Fig. 2): 


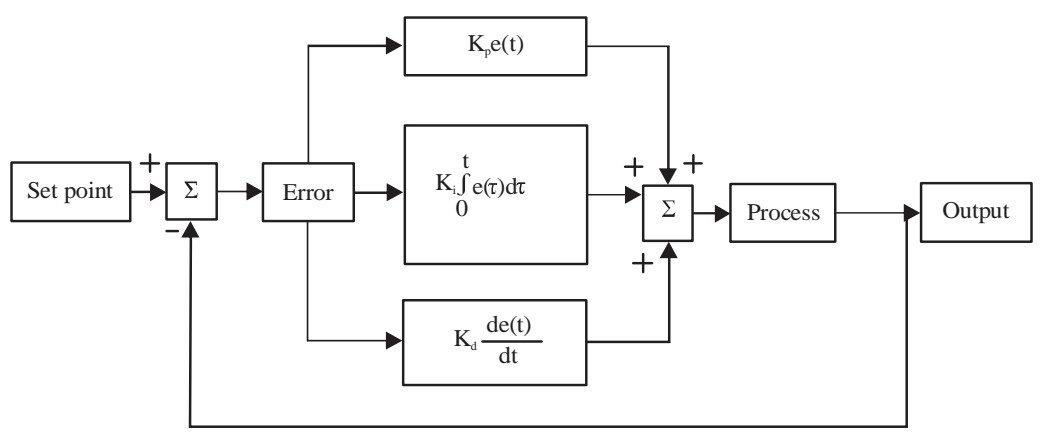

Fig. 2: Block diagram of PID controller

\begin{tabular}{lc} 
Table 1: Experimental data & \\
\hline Parameters & \multicolumn{1}{c}{ Values } \\
\hline Exchanger response to the steam flow gain & $5{ }^{\circ} \mathrm{C} / \mathrm{kg} / \mathrm{sec}$ \\
Time constants & $30 \mathrm{sec}$ \\
Exchanger response to variation of process & $3{ }^{\circ} \mathrm{C} / \mathrm{kg} / \mathrm{sec}$ \\
fluid flow gain & \\
Exchanger response to variation of process & $1{ }^{\circ} \mathrm{C} /{ }^{\circ} \mathrm{C}$ \\
temperature gain & \\
Control valve capacity & $0.16 \mathrm{~kg} / \mathrm{sec}$ \\
Time constant of control valve & $3 \mathrm{sec}$ \\
The range of temperature sensor & $50-150^{\circ} \mathrm{C}$ \\
Time constant of temperature sensor & $10 \mathrm{sec}$ \\
\hline & \\
Table 2: Transfer function of heat exchanger system & \multicolumn{2}{c}{ Transfer function } \\
\hline Parameters & $50 / 30 \mathrm{~s}+1$ \\
Transfer function of process & 0.13 \\
Gain of valve & $0.13 / 3 \mathrm{~s}+1$ \\
Transfer function of valve & 0.75 \\
Gain of current to pressure converter & $1 / 30 \mathrm{~s}+1,3 / 30 \mathrm{~s}+1$ \\
Transfer function of disturbance variables & \\
(flow and temperature disturbances, respectively) & \\
Transfer function of temperature sensor & $0.16 / 10 \mathrm{~s}+1$ \\
\hline
\end{tabular}

Table 3: Ziegler-Nichols method for calculation of PID controller (Ang et al., 2005)

\begin{tabular}{llll}
\multicolumn{2}{c}{ (Ang et al., 2005) } & $\mathrm{T}_{\mathrm{i}}$ & $\mathrm{T}_{\mathrm{d}}$ \\
\hline Variables & $\mathrm{K}_{\mathrm{n}}$ & Infinite & 0 \\
P controller & $0.5 \mathrm{~K}_{\mathrm{c}}$ & $\mathrm{T} / 1.2$ & 0 \\
PI controller & $0.45 \mathrm{~K}_{\mathrm{c}}$ & $\mathrm{T} / 2$ & $\mathrm{~T} / 8$ \\
PID controller & $0.6 \mathrm{~K}_{c}$ &
\end{tabular}

$$
\mathrm{u}(\mathrm{t})=\mathrm{k}_{\mathrm{c}}\left(\mathrm{e}(\mathrm{t})+\frac{1}{\tau_{\mathrm{i}}} \int_{0}^{\mathrm{t}} \mathrm{e}(\mathrm{t}) \mathrm{dt}+\tau_{\mathrm{d}} \frac{\mathrm{de}(\mathrm{t})}{\mathrm{dt}}\right)
$$

The general block diagram of PID controller:

Tuning method of PID controller: Ziegler-Nichols is a popular tuning method of PID controller for determining the PID parameters value of $K_{p}, T_{i}$ and $T_{d}$ based on the steady state response characteristics of shell-and-tube type heat exchanger system (Table 3). The characteristic equation of the plant:

$$
1+\mathrm{G}(\mathrm{s}) \mathrm{H}(\mathrm{s})=0
$$

$\mathrm{G}(\mathrm{s})$ and $\mathrm{H}(\mathrm{s})$ is process and sensor transfer function:

$$
1+\frac{5}{90 s^{2}+33 s+1} * \frac{0.16}{10 s+1}=0
$$

PID controller parameters values obtained using the Ziegler-Nichols tuning method is (Table 4):

$$
\mathrm{K}_{\mathrm{p}}=14.28 \mathrm{~T}_{\mathrm{i}}=14.395 \mathrm{~T}_{\mathrm{d}}=3.59
$$

Manual tuning is also a method of tuning PID controller. Firstly, value of $\mathrm{P}$ is increased until the:

$$
900 s^{3}+400 s^{2}+43 s+0.8 K_{c}+190=0
$$

The application of Routh stability criteria on the above equation gives $K_{c}=23.8$. Auxiliary equation:

$$
400 \mathrm{~s}^{2}+0.8 \mathrm{~K}_{\mathrm{c}}+1=0
$$

Substituting $s=j \omega$ in auxiliary Eq. $4 \omega=0.218$ and $\mathrm{T}=28.8$ output start oscillating and by keeping value of Integral (I) and Derivative (D) controller to zero. Then start increasing the value of I to improve steady state error but value of I must be in optimum range. The increase in value of I to certain limit causes instability. And then, the value of $\mathrm{D}$ is increased if required, $\mathrm{D}$ improves the stability of system.

Fuzzy logic controller: The design of fuzzy logic controller is implemented in shell-and-tube heat exchanger system. Fuzzy logic controller is a control algorithm based on a linguistic control strategy (Fig. 3). Fuzzy system in comparison with other control systems does not demand for complex mathematical calculation (Pandey et al., 2012). Fuzzy logic controllers have many control gains in their structures. These gains are computed and adjusted with respect to non linear function of the error and rate of change of error. Input variables of fuzzy logic controller in MATLAB Simulink are error e(t) and rate of change of error $\mathrm{e}(\mathrm{t})$. Output variable is the controller output $\mathrm{u}(\mathrm{t})$. The rule base of 9 membership function for fuzzy is shown in Table 5.

Here, VBN shows very big negative, NB shows Negative Big, NM shows Negative Medium, NS show Negative Small, Z indicates Zero, PS shows Positive Small, PM show Positive Medium, PB shows Positive Big, VBP shows Very Big Positive. The rule base is used 
Int. J. Soft Comput., 14 (4): 77-85, 2019

Table 4: Effect of PID parameters on system

\begin{tabular}{lllll} 
Parameters & Overshoot & Settling time & Steady-state error & Stability \\
\hline $\mathrm{K}_{\mathrm{p}}$ & Increase & Small change & Decrease & Degrade \\
$\mathrm{K}_{\mathrm{I}}$ & Increase & Increase & Decrease significantly & Degrade \\
$\mathrm{K}_{d}$ & Minor decrease & Minor decrease & No theoretical effect & Improve \\
\hline
\end{tabular}

Table 5: The rule base of 9 membership function

\begin{tabular}{|c|c|c|c|c|c|c|c|c|c|c|}
\hline \multirow[b]{2}{*}{$\mathrm{u}(\mathrm{t})$} & \multicolumn{10}{|l|}{$\mathrm{e}(\mathrm{t})$} \\
\hline & Variables & VBN & NB & NM & NS & $\mathrm{Z}$ & PS & $\mathrm{PM}$ & $\mathrm{PB}$ & VBP \\
\hline \multirow{9}{*}{$\overline{\Delta \mathrm{e}(\mathrm{t})}$} & VBN & VBN & VBN & VBN & VBN & VBN & NB & NM & NS & Z \\
\hline & NB & VBN & VBN & VBN & VBN & NB & NM & NS & Z & PS \\
\hline & NM & VBN & VBN & VBN & NB & NM & NS & Z & PS & PM \\
\hline & NS & VBN & VBN & NB & NM & NS & Z & PS & PM & $\mathrm{PB}$ \\
\hline & Z & VBN & NB & NM & NS & $\mathrm{Z}$ & PS & PM & PB & VBP \\
\hline & PS & NB & NM & NS & Z & PS & PM & PB & VBP & VBP \\
\hline & PM & NM & NS & $\mathrm{Z}$ & PS & PM & PB & VBP & VBP & VBP \\
\hline & PB & NS & Z & PS & PM & PB & VBP & VBP & VBP & VBP \\
\hline & VBP & Z & PS & PM & PB & VBP & VBP & VBP & VBP & VBP \\
\hline
\end{tabular}

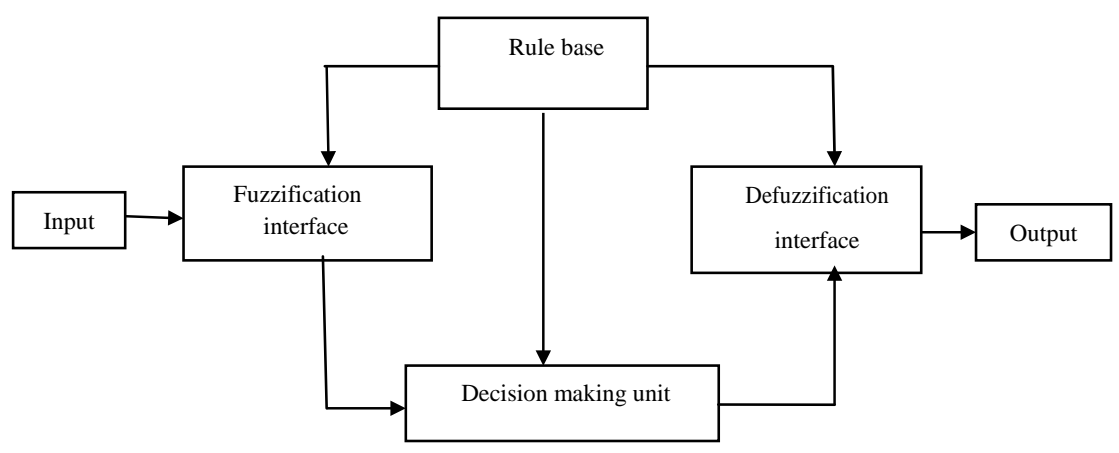

Fig. 3: Block diagram of fuzzy logic controller

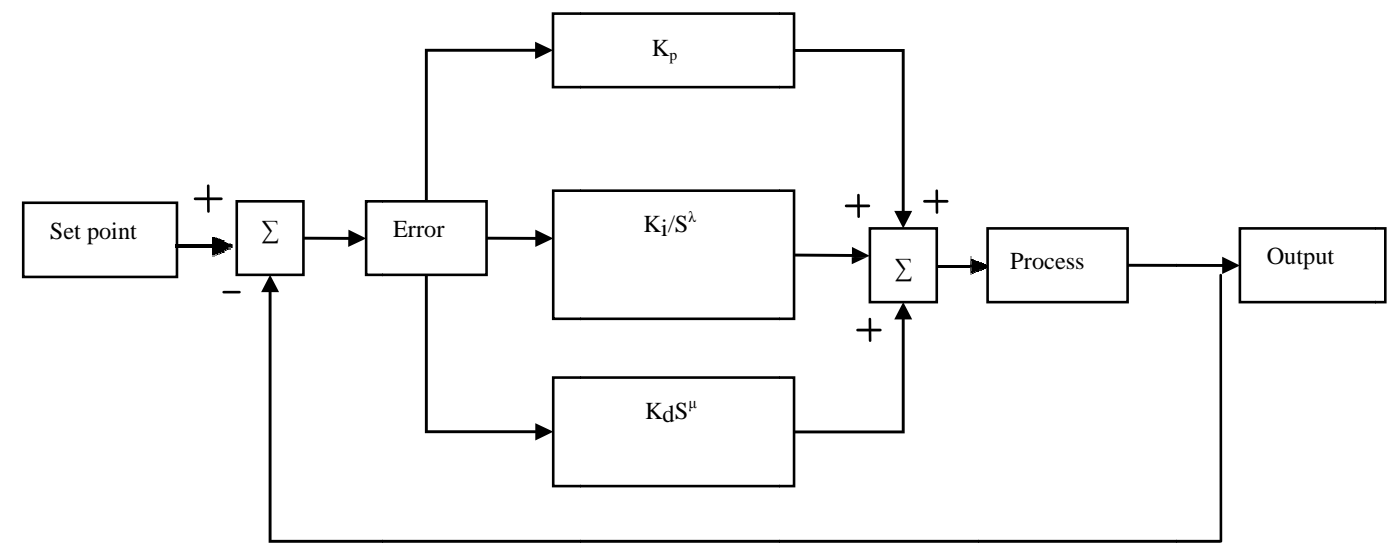

Fig. 4: Block diagram of Fractional-Order PID (FOPID) controller

in MATLAB Simulink and designing a good fuzzy logic rule is the key to obtain a better performance of the shell-and-tube heat exchanger system. Each rule of fuzzy controller in the form of if e(t) is VBN and e(t) is VBN then $u(t)$ is VBN. At last centroid method is used to obtain defuzzified output from the fuzzy input.

Fractional-order PID (FOPID) controller: The general form of fractional-order PID controller is the Pi $\lambda \mathrm{D} \mu$. Integer order controller is commonly used for industrial application but now a day's fractional order PID controller is also used in process industries for better performance of the system. Time domain equation for fractional-order PID controller is shown in Fig. 4:

$$
G(t)=K_{p} e(t)+K_{i} D^{-\lambda} e(t)+K_{d} D^{\mu} e(t)
$$

The fractional-order PID controller in the form of transfer function is given below: 


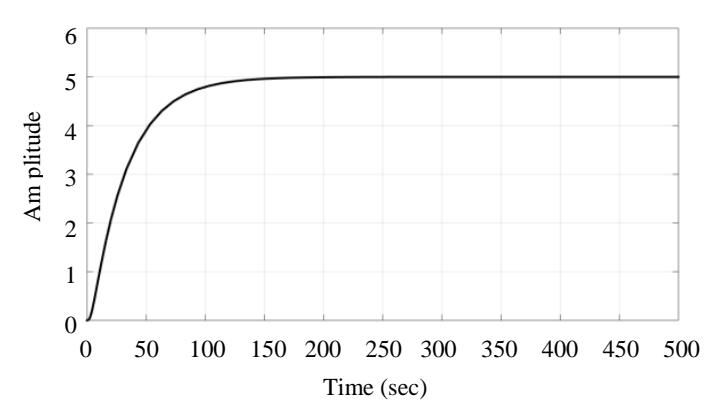

Fig. 5: Step open-loop response of heat exchanger without disturbance PID controller

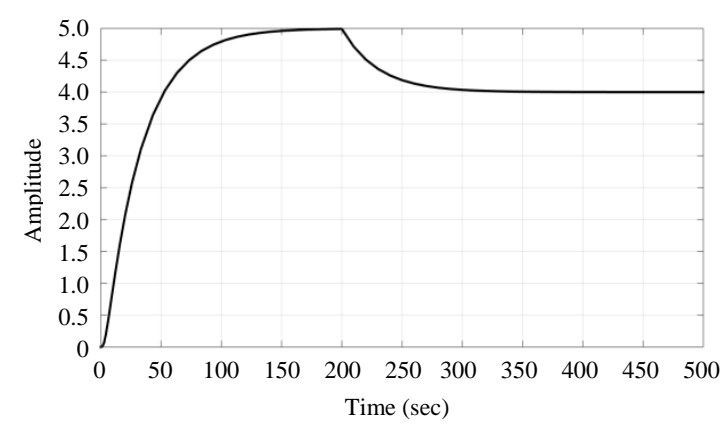

Fig. 6: Step open-loop response of heat exchanger with disturbance PID controller

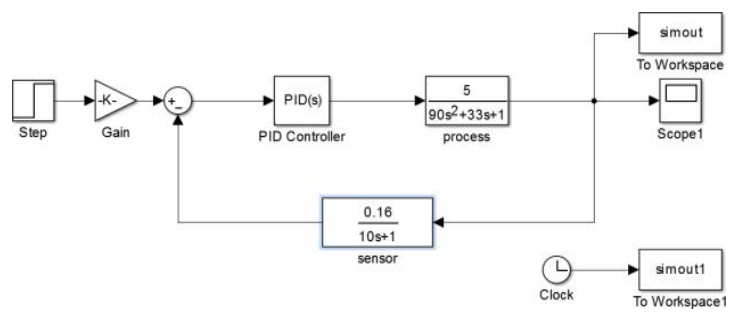

Fig. 7: Simulink model of shell-and-tube heat exchanger without disturbance PID controller

$$
\mathrm{G}(\mathrm{s})=\mathrm{K}_{\mathrm{p}}+\mathrm{K}_{\mathrm{i}} / \mathrm{s}^{\lambda}+\mathrm{K}_{\mathrm{d}} \mathrm{s}^{\mu}
$$

Here, instead of integer PID parameters $\left(\mathrm{K}_{\mathrm{p}}, \mathrm{K}_{\mathrm{i}}\right.$ and $K_{d}$ ) two additional fractional parameters lambda $(\lambda)$ and mu $(\mu)$ are used. Fractional order yields two extra degrees of freedom. Fractional-order PID controller parametric values are obtained by optimization using MATLAB FOMCON (Fractional-Order Modeling and Control) toolbox (Tepljakov et al., 2013; Mukherjee et al., 2016).

Simulation and testing: The simulations for the open-loop response, closed loop response with different controllers with and without disturbance are discussed and realized using Simulink in MATLAB 2015a. Figure 5 and 6 express the step response of open-loop shell and tube heat exchanger system with and without load disturbance. Figure 7-12 express the block diagram of controllers of the shell-and-tube heat exchanger system with and without disturbance. A step load disturbance is introduced at $\mathrm{t}=200 \mathrm{sec}$ creating a sudden transient change in step response at $t=200$ sec. Figure 13-18 express the steady state response of heat exchanger system. The controller then achieves steady state value from the load disturbance transient after a certain time period.

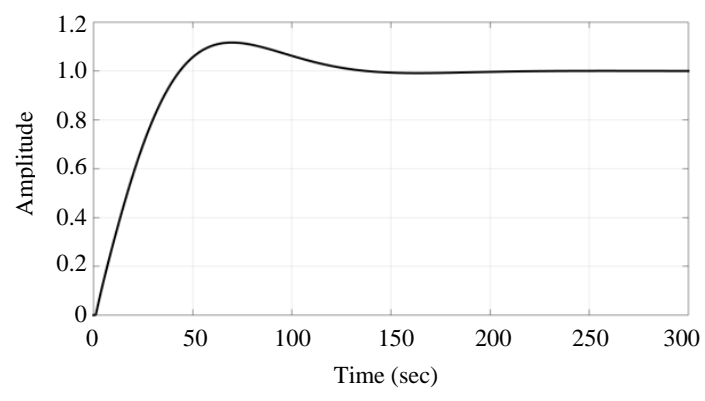

Fig. 8: Step response of heat exchanger without disturbance PID controller

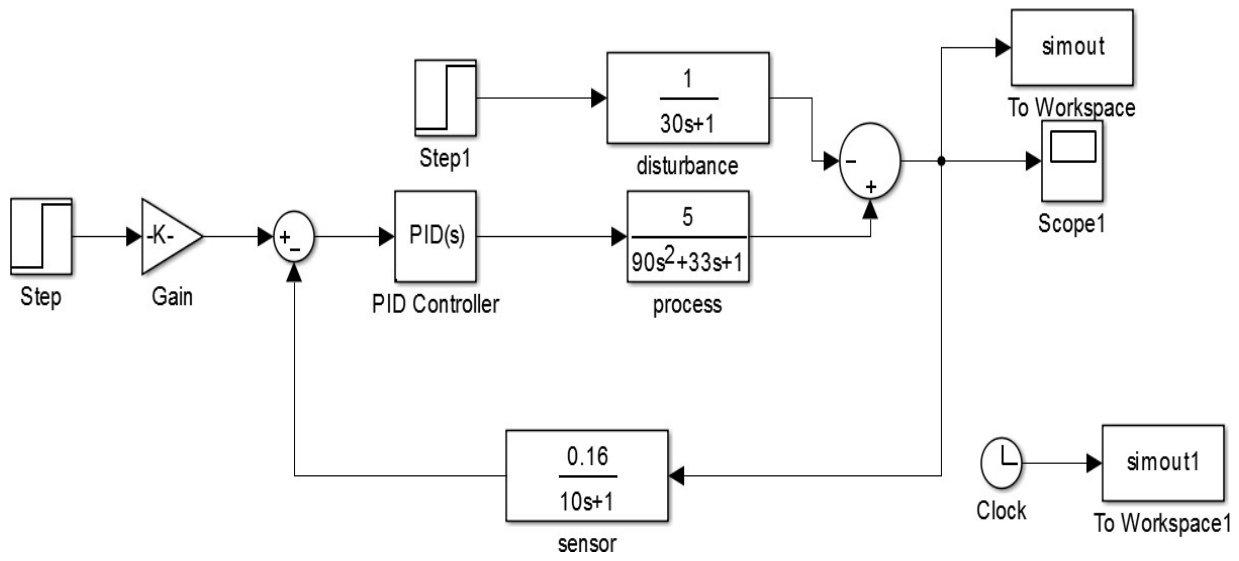

Fig. 9: Simulink model of shell-and-tube heat exchanger with disturbance PID controller 
Int. J. Soft Comput., 14 (4): 77-85, 2019

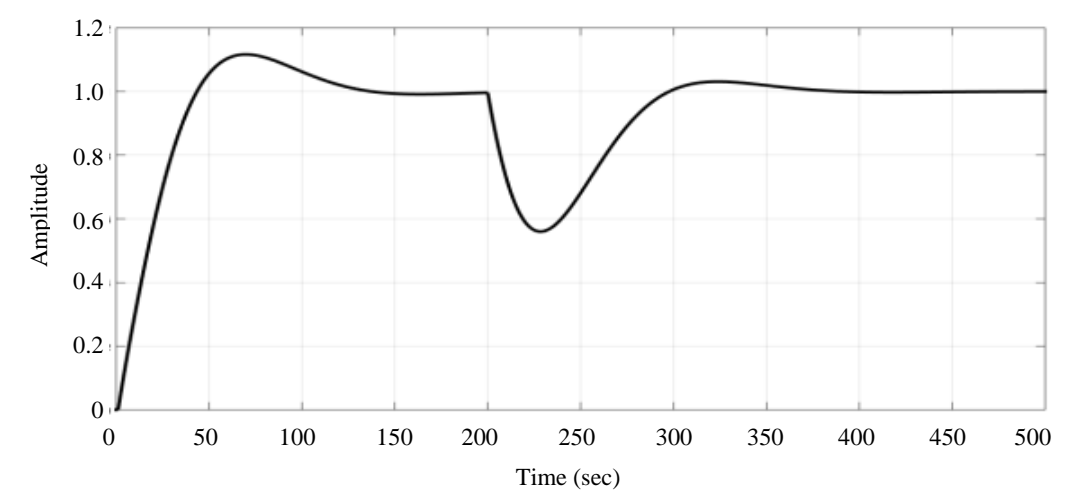

Fig. 10: Step response of heat exchanger with disturbance PID controller

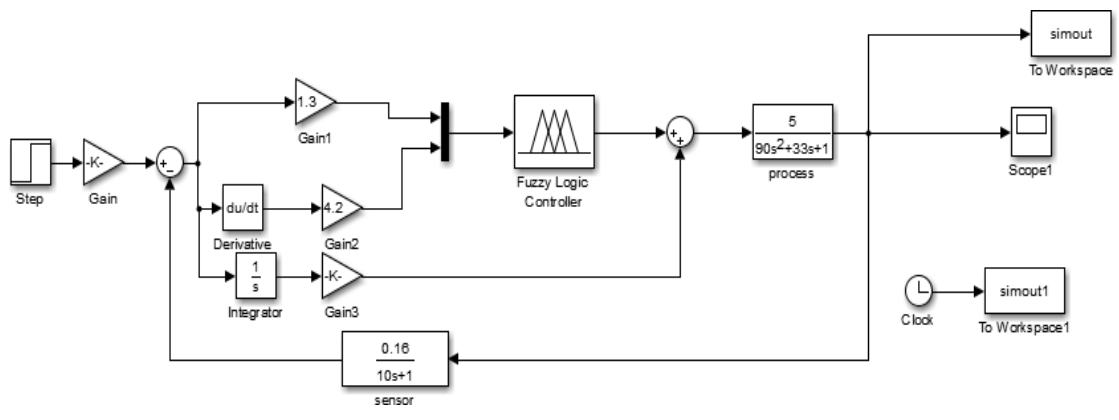

Fig. 11: Simulink model of shell-and-tube heat exchanger without disturbance fuzzy controller

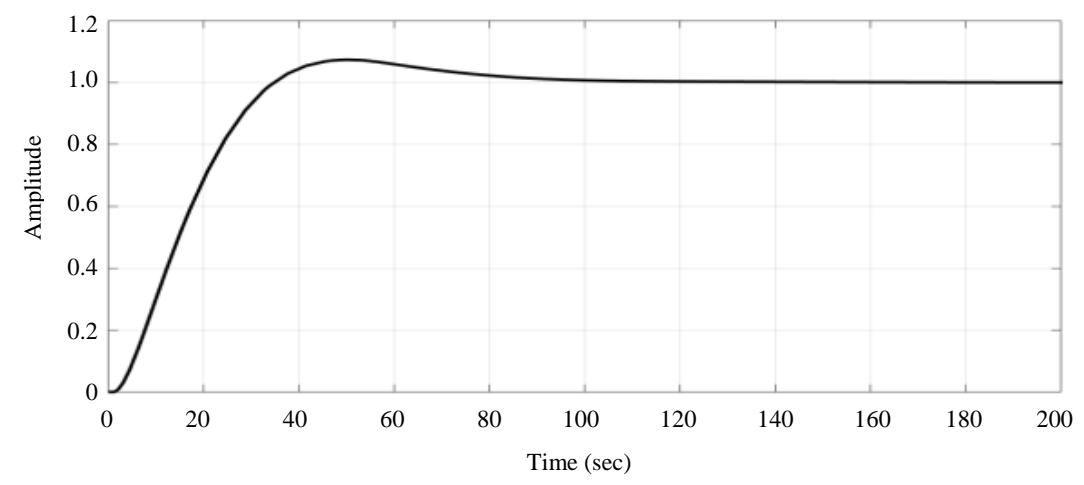

Fig. 12: Step response of heat exchanger without disturbance fuzzy controller

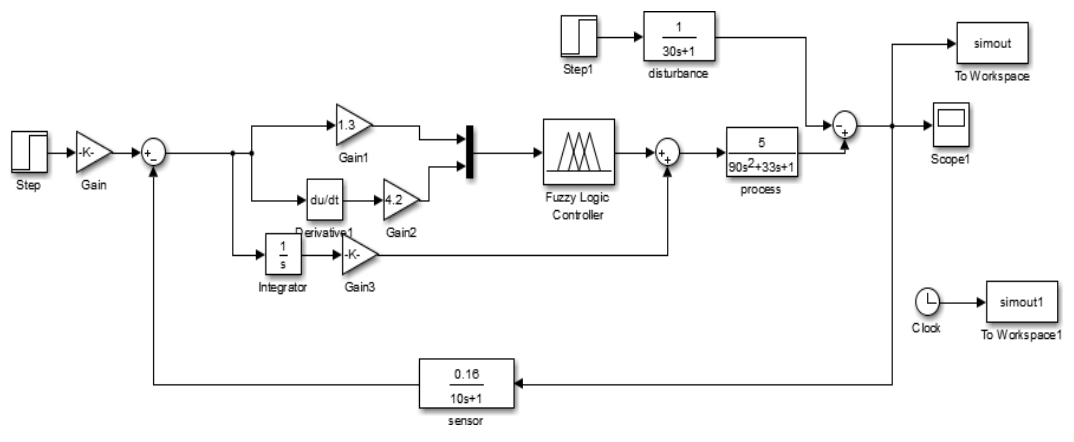

Fig. 13: Simulink model of shell-and-tube heat exchanger with disturbance fuzzy controller 
Int. J. Soft Comput., 14 (4): 77-85, 2019

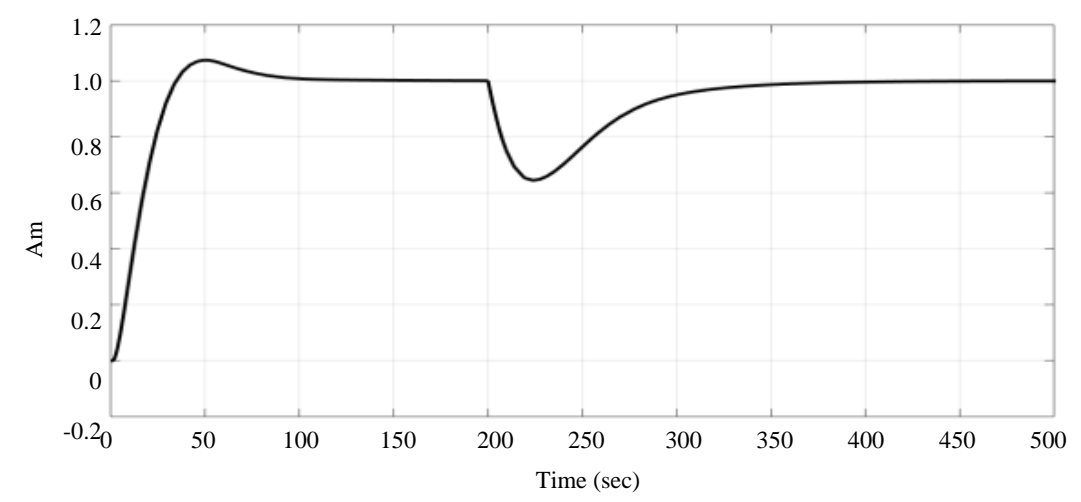

Fig. 14: Step response of heat exchanger with disturbance fuzzy controller

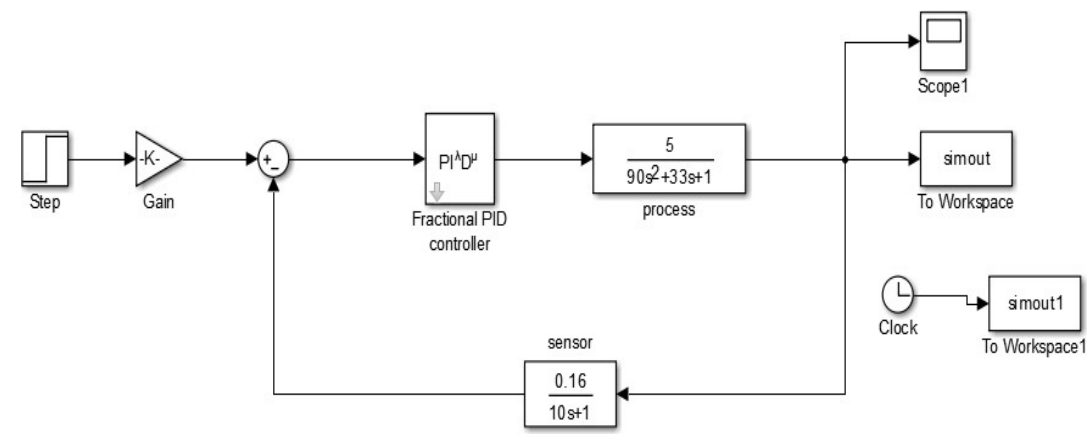

Fig. 15: Simulink model of shell-and-tube heat exchanger without disturbance FOPID controller

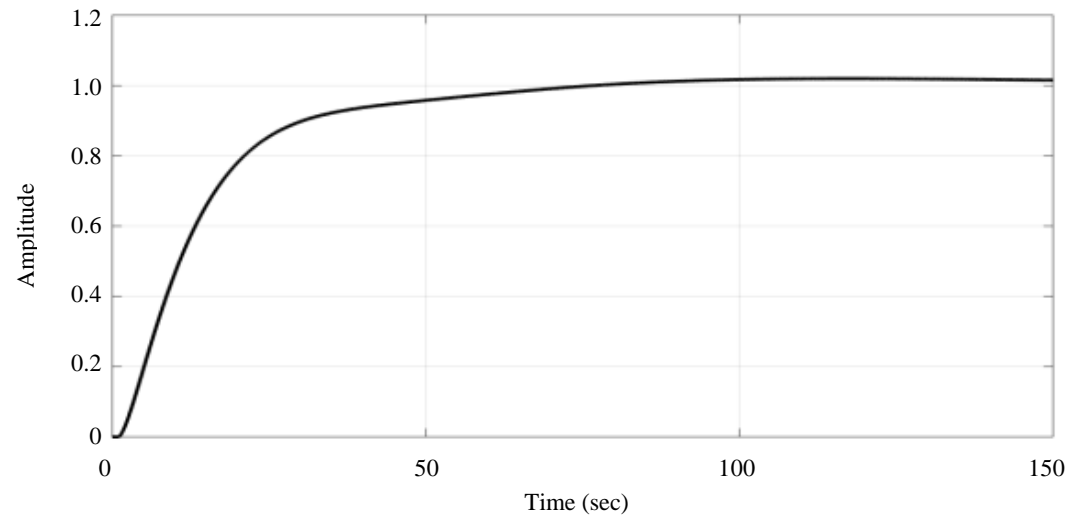

Fig. 16: Step response of heat exchanger without disturbance FOPID controller

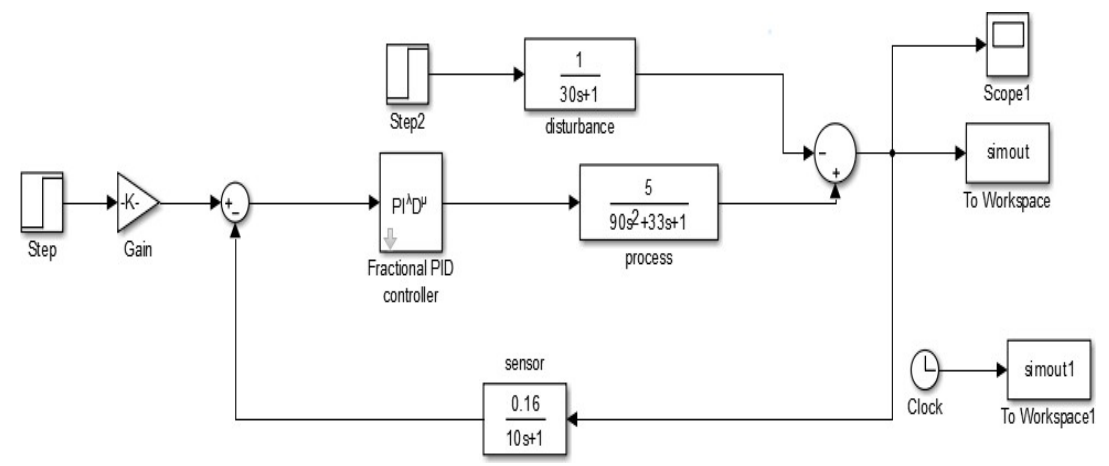

Fig. 17: Simulink model of shell-and-tube heat exchanger with disturbance FOPID controller 


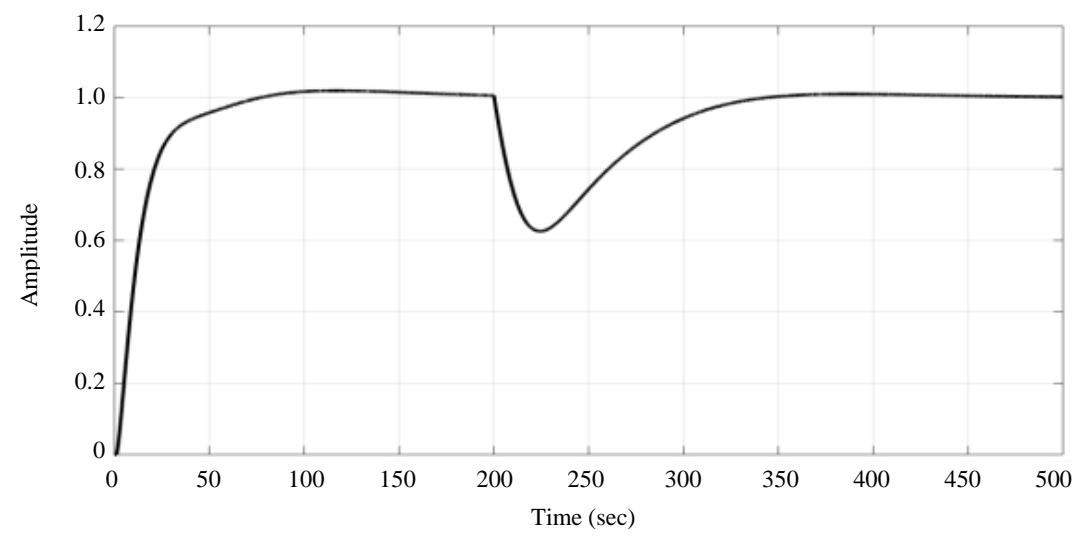

Fig. 18: Step response of heat exchanger with disturbance FOPID controller

$\begin{aligned} & \text { Table 6: Steady state response analysis of different controllers (Without } \\
& \text { disturbance) }\end{aligned}$
\begin{tabular}{lcc}
\hline Controller & Peak overshoot (\%) & Settling time (sec) \\
\hline Open-loop & 0.0 & 120.0 \\
PID & 11.6 & 120.0 \\
Fuzzy (9 membership) & 7.4 & 79.6 \\
Fractional order PID & 1.9 & 62.0 \\
\hline
\end{tabular}

Table 7: Steady state response analysis of different controllers (With disturbance at $\mathrm{t}=200 \mathrm{sec}$ )

\begin{tabular}{lcc}
\hline Controller & Peak overshoot (\%) & Settling time (sec) \\
\hline Open-loop & 0.0 & 300.0 \\
PID & 11.6 & 348.7 \\
Fuzzy (9 memberships) & 7.4 & 329.4 \\
Fractional order PID & 1.9 & 321.0 \\
\hline
\end{tabular}

\section{RESULTS AND DISCUSSION}

This study is performed to evaluate the performance of the shell-and-tube heat exchanger system with open-loop, PID, FOPID and fuzzy logic controller with and without disturbance. This study has considered two parameters: maximum peak overshoot and settling time of the steady state response of the shell-and-tube type heat exchanger system. A comparative study of these controllers with open-loop response with and without load disturbance performance has been shown in Table 6 and 7.

Figure 5 concludes that the open-loop response of the system has a very high steady state of error, so, needs a controller to overcome this error. From the above results, PID controller with and without disturbance produces a maximum peak overshoot of $11.6 \%$ which is undesirable for a system. That is why implementation of fuzzy logic controller and Fractional-Order PID (FOPID) controller is done to obtain desired results. Maximum peak overshoot is $7.4 \%$ in fuzzy and $1.9 \%$ in FOPID for with and without disturbance of heat exchanger system. Settling time of PID controller for with and without disturbance is 120 and $348.7 \mathrm{sec}$ which is high. Settling time of fuzzy controller for with and without disturbance is 79.6 and $329.4 \mathrm{sec}$; it gives better response than PID controller. Fractional-Order PID controller gives low peak overshoot $1.9 \%$ and low settling time 62 sec without load disturbance and $321 \mathrm{sec}$ with load disturbance when compared with PID controller and fuzzy logic controller for with and without load disturbance of shell-and-tube heat exchanger system. FOPID gives quick response without any oscillations.

\section{CONCLUSION}

This study takes up a comparative study of shelland-tube heat exchanger system with different controllers and evaluates controlling of the outlet fluid temperature at a desired set point level. Three different types of controllers are controlling the outlet fluid temperature with and without load disturbance to a desired temperature in minimum peak overshoot and low settling time. The performances of different controllers are evaluated using steady state response. From the simulation results, fractional-order PID controller has a superior performance than PID controller and fuzzy logic controller.

\section{REFERENCES}

Ang, K.H., G. Chong and Y. Li, 2005. PID control system analysis, design and technology. IEEE Trans. Control Systems Technol., 13: 569-576.

Duran, O., N. Rodriguez and L.A. Consalter, 2008. Neural networks for cost estimation of shell and tube heat exchangers. Proceedings of the International Multi Conference on Engineers and Computer Scientists (IMECS’08) Vol. 2, March 19-21, 2008, Hong Kong, pp: 1-6. 
Gopal, M., 2012. Control Systems. Tata McGraw- Hill Education, New Delhi, India,.

Ismail, E.E., R. Abdelrassoul, A. Abdelbary and O.M. ElSaid, 2015. Improving the performance of heat exchanger system by better control circuits. Int. J. Comput. Appl., 121: 57-63.

Khare, Y.B. and Y. Singh, 2010. PID control of heat exchanger system. Int. J. Comput. Appl., 8: 22-27.

Mukherjee, D., P.K. Kundu and A. Ghosh, 2016. PID controller design for an interacting tank level process with time delay using MATLAB FOMCON toolbox. Proceedings of the 2016 2nd International Conference on Control, Instrumentation, Energy \& Communication (CIEC'16), January 28-30, 2016, IEEE, Kolkata, India, pp: 1-5.

Padhee, S., 2014. Controller design for temperature control of heat exchanger system: Simulation studies. WSEAS. Trans. Syst. Contr., 9: 485-491.
Padhee, S., Y.B. Khare and Y. Singh, 2011. Internal model based PID control of shell and tube heat exchanger system. Proceedings of the IEEE International Symposium on Technology Students, January 14-16, 2011, IEEE, Kharagpur, India, pp: 297-302.

Pandey, M., K. Ramkumar and V. Alagesan, 2012. Design of fuzzy logic controller for a cross flow shell and tube heat-exchanger. Proceedings of the IEEE International Conference on Advances in Engineering, Science and Management (ICAESM'12), March 30-31, 2012, IEEE, Nagapattinam, Tamil Nadu, India, pp: 150-154.

Tepljakov, A., E. Petlenkov, J. Belikov and J. Finajev, 2013. Fractional-order controller design and digital implementation using FOMCON toolbox for MATLAB. Proceedings of the 2013 IEEE International Conference on Computer Aided Control System Design (CACSD’13), August 28-30, 2013, IEEE, Hyderabad, India, pp: 340-345. 